\title{
The Association between Helicobacter pylori and Graves' Disease
}

\author{
Taghrid Mohamed Abdalla ${ }^{1}$, Fayrouz Othman Selim ${ }^{2}$ and Thoraya Hosny ${ }^{3}$ \\ Tropical Medicine ${ }^{1}$, Internal Medicine $e^{2}$ and Clinical Pathology ${ }^{3}$ Departments, \\ Faculty of Medicine, Zagazig University.
}

\section{Corresponding Author Taghrid Mohamed Abdalla}

Mobile:

00201014616211

E mail:

tagkomy@gmail.com

Key words:

Helicobacter pylori,

Graves' disease, autoimmune, thyroid.
Background and study aim: Helicobacter pylori (H. pylori) infection is a very common health problem associated with both gastric and extra gastric manifestations. Its association with autoimmune thyroid diseases (ATD) including Graves' Disease (GD) was suspected and needed to be furtherly investigated.

Patients and Methods: This case - control study included 43 patients with GD and a control group of 47 healthy volunteers. Hormonal diagnosis of GD was achieved by decreased level of thyroid stimulating hormone (TSH) and elevated levels of triiodothyronine (FT3) and free thyroxine (FT4) and serological diagnosis was achieved by positive titers of autoantibodies against thyroglobulin (TG
Abs), thyroid peroxidase (TPO Abs) and thyrotropin receptor (TR Abs). H. pylori infection was diagnosed by detecting $H$. pylori antigens in stool using an amplified enzyme immunoassay (amplified EIA). The antibodies against Cytotoxin-associated gene A (Cag-A) were assessed in serum samples using the enzyme-linked immunosorbent assay method (ELISA). The results were statistically analyzed using Fisher's test and the respective Odd's ratio (OR)

Results: No significant difference in prevalence of $H$. pylori infection was found between GD patients and the control group.

Conclusion: No association between $H$. pylori infection and Graves' disease could be detected.

\section{INTRODUCTION}

Helicobacter pylori (H. pylori) is a worldwide chronic infection [1,2]. It is a Gram - negative spiral pathogen that inhabits the gastric mucosa causing multiple gastric diseases such as chronic gastritis, peptic ulcers, and gastric malignancies $[\mathbf{3 , 4}]$. It was also incriminated in both organ specific and non-organ specific autoimmune disease [5]. H. pylori was also involved in many extra gastric diseases such as nonalcoholic fatty liver diseases and metabolic syndrome [6,7]. Many available data links autoimmune thyroid diseases (ATD)- particularly Graves' disease (GD)- with $H$. pylori infection [8]. A strong association between thyroid auto- antibodies and immunoglobulin $\mathrm{G}$ (IgG) anti- $H$. pylori antibodies was reported. Radical treatment of $H$. pylori infection was found to be associated with a gradual drop in the levels of thyroid autoantibodies, however these data are still controversial [9-11]. Moreover, thyroid nodules were found to be associated with $H$ pylori infection in people with normal thyroid functions [12]. Cytotoxin-associated gene A (Cag A) strain accounts for most of $H$. pylori seropositive infection $(89.2 \%)$ [13]. The mechanism by which $H$. pylori infection induces ATD was supposed to be a cross - reactivity between bacterial and thyroid antigens [14]. The ability of $H$. pylori infection to imitate the antigenic pattern of thyroid cell membrane has been suggested $[15,16]$. Multiple data - about similarities between amino acid sequence of $H$. pylori Cag-A and thyroid peroxidase (TPO) - have been published [17]. Typical markers of GD include the assessment of autoantibodies against thyroid peroxidase (TPO Abs), thyroglobulin (TG Abs) and thyrotropin receptor (TR Abs) [18].

This work aims at investigating the relationship between GD and $H$. pylori infection and whether there is any association in between.

Abdalla et al., Afro-Egypt J Infect Endem Dis 2018; 8(4):196-201

https://aeji.journals.ekb.eg/

http://mis.zu.edu.eg/ajied/home.aspx 


\section{PATIENTS AND METHODS}

This is a collaborate work between Tropical Medicine Department, Internal Medicine Department and Clinical Pathology Department, Faculty of Medicine Zagazig University. A oneyear study was conducted in the period from January, 2017 to January, 2018.

A total number of 43 patients with GD (7 males and 36 females) and a control group of 47 healthy individual (27 females and 20 males) were enrolled in a case- control study over one year. The inclusion criteria included any patient with GD, while exclusion criteria included the presence of other diseases, history of antimicrobial drugs use for at least the preceding three months, presence of gastric diseases and dyspeptic symptoms (nausea, heartburn, and epigastric pain). Both groups were of the same body - mass index (BMI), socioeconomic status and inclusion criteria.

GD patients were selected based on their positive hormonal hyperthyroidism profile - including suppressed thyroid stimulating hormone (TSH), elevated free tri-iodothyronine (FT3), elevated free thyroxine (FT4) and positive titers of TPO Abs, TG Abs and TR Abs. They were measured by electrochemiluminescence immunoassay (ECLIA) on cobas immunoassay analyzers. Anti TG titer above $50 \mathrm{ng} / \mathrm{ml}$ and anti TPO above 200 $\mathrm{IU} / \mathrm{ml}$ were considered positive. The control group individuals were confirmed to have normal TSH, FT3 and FT4, and to be free from autoantibodies against TPO, TG and TR. Also, thyroid ultrasound was done to assess the presence of goiter and to exclude thyroid nodules. Both groups were subjected to thorough history taking and clinical examination, then they underwent the following:

- H. pylori antigens were detected in fresh stool samples by amplified enzyme immunoassay (Amplified IDEIA $H$. pylori StAR, Oxoid, United Kingdom). Positive results were confirmed for the presence of $H$. pylori with an absorbance value $>0.150$ using a dual wavelength (450/ 620 to 650 nanometers).

- Anti - Cag-A IgG antibodies were detected in fresh serum samples by the enzyme-linked immunosorbent assay method (ELISA, Radim, Pomezia, Italy, sensitivity $93.7 \%$, specificity $100 \%$ ). An IgG level $>15$ units $/ \mathrm{mL}$ was considered positive.

\section{Statistical analysis:}

The statistical analysis of results was carried out by an experienced epidemiologist. It was achieved using the SPSS version 19 considering $P$ value $<0.05$ as statistically significant. The Chi-square or Fisher exact test were used to assess differences in proportions among categorical data. The independent impact of $H$. pylori on GD was assessed by multivariate analysis. On univariate analysis, variables with a $P$ value of $<0.2$ were included in the multivariate analysis using Logistic regression for this purpose. Odds ratios (OR) with a confidence interval (CI) of $95 \%$ were reported. Median and interquartile range (IQR) were used to represent continuous variables.

\section{RESULTS}

A collaborate work was conducted over one year between Tropical Medicine Department and Internal Medicine Department, Faculty of Medicine Zagazig University. Forty-three GD patients were included in the study along with 47 healthy control individuals.

The study groups were classified into age and sex subgroups (range $=18-65$ years). No statistically significant difference was found between both groups regarding age or sex (Table 1).

The mean, median and range of the body mass index showed no significant differences between the GD group and the control group (Table 2).

The prevalence of $H$. pylori +ve stool Ag was found to be more among GD patients' group (46.5\%) than the control group (42.6\%), but the difference was statistically insignificant. The prevalence of Cag A antibodies among the study groups was found to be more among $H$. pylori +ve stool Ag of the control group (30\%) than the H. pylori +ve stool Ag of GD patients' group (20\%), but the difference was statistically insignificant (Table 3).

H. pylori was more prevalent among the age subgroup of 40- 59 years of both GD patients and the control group but the difference was statistically insignificant (Table 4).

The prevalence of $H$. pylori was not associatedwith GD (OR 1.02, 95\% CI 0.57$1.83, P=0.95)$, but the family thyroid malfunction was found to be a risk factor independently associated with GD (OR $=3.93,95 \%$ CI was 1.86- 618, and $P<0.001$ ) (Table 5). 
Table (1): Classification of patients and control groups according to age and sex.

\begin{tabular}{|c|c|c|c|c|c|}
\hline \multirow[b]{2}{*}{ Age } & \multicolumn{2}{|c|}{$\begin{array}{l}\text { GD group } \\
\quad(n=43)\end{array}$} & \multicolumn{2}{|c|}{$\begin{array}{l}\text { Control group } \\
\qquad(n=47)\end{array}$} & \multirow[t]{2}{*}{$\boldsymbol{P}$} \\
\hline & $\begin{array}{c}\text { Female } \\
n=36\end{array}$ & $\begin{array}{c}\text { Male } \\
n=7\end{array}$ & $\begin{array}{c}\text { Female } \\
n=27\end{array}$ & $\begin{array}{l}\text { Male } \\
\mathbf{n}=\mathbf{2 0}\end{array}$ & \\
\hline $18-20$ years & $7(19.4 \%)$ & $0(0 \%)$ & $7(25.9 \%)$ & $4(20 \%)$ & \multirow{4}{*}{0.159} \\
\hline$>20-39$ years & $10(27.7 \%)$ & $3(42.8 \%)$ & $9(33.3 \%)$ & $7(35 \%)$ & \\
\hline $40-59$ years & $8(22.2 \%)$ & $1(14.2 \%)$ & $6(22.2 \%)$ & $5(25 \%)$ & \\
\hline $60-65$ years & $11(36.6 \%)$ & $3(42.8 \%)$ & $5(18.5 \%)$ & $4(20 \%)$ & \\
\hline
\end{tabular}

GD: graves' Disease.

Table (2): Comparison between the two study groups regarding the body- mass index (BMI).

\begin{tabular}{|c|c|c|c|}
\hline $\mathrm{PMI}_{\text {BMI }}^{\text {Study groups }}$ & $\begin{array}{c}\text { GD } \\
\mathrm{N}=43\end{array}$ & $\begin{array}{c}\text { Control } \\
\mathrm{N}=47\end{array}$ & $\boldsymbol{P}$ \\
\hline Mean (SD) & $25.5 \pm(5.4)$ & $25.2 \pm(5.2)$ & \multirow{3}{*}{0.801} \\
\hline Median (IQR) & $24.6(21.5-28)$ & $23.9(21.2-28.9)$ & \\
\hline Range & $16.8-44.4$ & $16.4-43.7$ & \\
\hline
\end{tabular}

$\mathrm{IQR}=$ interquartile ratio $\quad \mathrm{SD}=$ standard deviation. $\quad$ GD: graves' Disease. $\quad$ BMI: body- mass index

Table (3): Comparison between the two study groups regarding the distribution of $H$. pylori stool $\mathrm{Ag}$ and serum Cag A-antibodies

\begin{tabular}{|l|c|c|c|c|c|}
\hline Study groups & $\begin{array}{c}\text { Stool Ag } \\
+ \text { pye }\end{array}$ & $\begin{array}{c}\text { Stool Ag } \\
- \text {-ve }\end{array}$ & $\begin{array}{c}\text { Anti- Cag A } \\
\text { +ve }\end{array}$ & $\begin{array}{c}\text { Anti- Cag A } \\
\text {-ve }\end{array}$ & $\begin{array}{c}\text { +ve Anti- Cag A } \\
\text { (among the total } \\
\text { no. of } \\
\text { studied groups) }\end{array}$ \\
\hline $\mathbf{G D}$ & 20 & 23 & $4 / 20$ & $16 / 20$ & $4 / 43$ \\
$\mathbf{n = 4 3}$ & $46.5 \%$ & $53.5 \%$ & $\mathbf{2 0 \%}$ & $80 \%$ & $9.3 \%$ \\
\hline Control & 20 & 27 & $6 / 20$ & $14 / 20$ & $6 / 47$ \\
$\mathbf{n = 4 7}$ & $42.6 \%$ & $55.4 \%$ & $\mathbf{3 0 \%}$ & $70 \%$ & $12.7 \%$ \\
\hline $\boldsymbol{P}$ & 0.63 & $\begin{array}{c}\text { Not } \\
\text { calculated }\end{array}$ & 0.352 & Not & 0.41 \\
\hline
\end{tabular}

Ag: antigen.

Cag A: cytotoxin-associated gene A.

GD: Graves' Disease.

Table (4): Comparison between different age subgroups regarding the prevalence of $H$. pylori infection

\begin{tabular}{|c|c|c|c|}
\hline $\begin{array}{lll}\text { Age } & \text { H pylori } \\
\end{array}$ & $\begin{array}{l}\text { GD group } \\
\quad N=43\end{array}$ & $\begin{array}{c}\text { Control group } \\
\quad \mathbf{N}=\mathbf{4 7}\end{array}$ & $\boldsymbol{P}$ \\
\hline 18- 20 years & $3 / 7(42.8 \%)$ & $4 / 11(36.3 \%)$ & $>0.5$ \\
\hline$>20-39$ years & $6 / 13(46.1 \%)$ & $7 / 16(43.7 \%)$ & $>0.8$ \\
\hline 40- 59 years & $5 / 9(55.5 \%)$ & $6 / 11(54.5 \%)$ & $>1.0$ \\
\hline 60- 65 years & $6 / 14(42.8 \%)$ & $3 / 9(33.3 \%)$ & $>0.7$ \\
\hline
\end{tabular}

GD: Graves' Disease. 
Table (5): Multivariate analysis of risk factors associated with GD.

\begin{tabular}{|l|c|c|}
\hline \multicolumn{1}{|c|}{ Risk factors } & OR (95\% CI) & $\boldsymbol{P}$ \\
\hline $\begin{array}{l}\text { Univariate } \\
\text { H. pylori }\end{array}$ & $1.14(0.66-1.96)$ & 0.63 \\
\hline $\begin{array}{l}\text { Multivariate * } \\
\text { - H pylori }\end{array}$ & $1.02(0.57-1.83)$ & 0.95 \\
\cline { 2 - 3 } $\begin{array}{l}\text { - Family history of thyroid } \\
\text { diseases. }\end{array}$ & $3.93(1.86-618)$ & $<0.001^{*}$ \\
\hline
\end{tabular}

\section{DISCUSSION}

H. pylori is a Gram-negative motile organism that colonizes and infects the gastric mucosa causing multiple pathological conditions. Its virulence is mainly encountered with the Cag A antigen strains [19]. H. pylori - among other genetic or environmental factors - was involved in ATD [11,20,21]. ATD include GD, atrophic thyroiditis, Hashimoto's thyroiditis (HT), subacute lymphocytic thyroiditis (postpartum thyroiditis, PPT), painless thyroiditis (PT), or silent thyroiditis (ST) [22]. Accumulating information connected $\mathrm{H}$. pylori infection with ATD, especially with GD [8], and thyroid nodular formation in euthyroid patients [12]. This study aimed at evaluating the association between $H$. pylori infection and GD.

This study showed that the prevalence of $H$. pylori was more among GD patients' group than the control group, but the difference was statistically insignificant. Interestingly, the prevalence of $\mathrm{Cag}$ A antibodies was even found to be more among the control group than the GD group, but the difference was statistically non- significant. These results agree with that of Tomasi et al. Franceschi et al and Novikova et al $[\mathbf{2 3}, \mathbf{2 7}, \mathbf{2 8}]$ who found no correlation between $H$ pylori prevalence and ATD in their studies directed on participants of different ages and different environmental conditions.

On the other hand, these results do not agree with that of some studies $[8, \mathbf{1 1}, \mathbf{1 3}, \mathbf{1 5}, \mathbf{2 4 , 2 9 , 3 7 ]}$ who found marked correlation between $H$. pylori infection- especially the Cag A positive strainsand ATD especially GD. This can be explained be the different genetic or environmental factors of the different studies. In developing countries, the incidence of $H$. Pylori infection starts at earlier ages with eventual higher rates of prevalence than in developed countries that can mask the suggested association $[\mathbf{8 , 2 4 , 2 5}]$.
Moreover, certain HLA antigens were suspected to predispose for ATD following H. Pylori infection [26]. However, this association - in some studies - was not between GD and $H$. Pylori infection per se, but it was mainly between Cag A antibodies level and GD [25]. A cross reactivity was suggested between $\mathrm{Cag}$ A antibodies and TPO Abs explaining the over estimation of $H$. pylori infection among GD patients in these studies [14,17]. Some studies adopted the estimation of $H$. pylori antibodies as a clue for prevalence of $H$. pylori infection [11,29]. Their over estimation of $H$. pylori infection among GD patients can be attributed in some cases to a previous and not the current infection.

In this study, GD was found to be significantly associated with a family history of thyroid diseases. This finding coincides with that of other studies which mentioned that the incidence of GD clusters in families usually occurs separately or in association with HT [29-32]. This can be explained by sharing the same genetic or environmental factors by the family members.

There was no significant difference in $H$. pylori prevalence among the different age subgroups of both GD and control groups, coinciding with the study result of Haim et al who found no associated between age and $H$. pylori prevalence [33]. However, these results do not agree with some authors [34-36] who mentioned that $H$. pylori infection is usually acquired during childhood and increases with age, with rare possibility to attract new infection in adulthood. Again, this controversy can be explained by the different genetic and environmental factors under which the different studies were conducted.

Conclusion: There is no association between $H$. pylori infection and Graves' Disease. 


\section{Ethical approval:}

Informed consent was taken from each patient. The research protocol was duly approved by the ethical committee of Zagazig University Hospitals.

Funding: No funding.

Conflict oF interest: None

Acknowledgement: My colleagues in Tropical Medicine Department.

\section{REFERENCES}

1. Maleki D, Locke GR 3rd, Camiilleri M, Zinsmeister AR, Yawn BP, Leibson C, et al. Gastrointestinal tract symptoms among persons with diabetes mellitus in the community. Arch Intern Med. 2000; 160(18):2808-2816.

2. Marshall BJ and Warren JR. Unidentified curved bacilli in the stomach of patients with gastritis and peptic ulcerations. Lancet. 1984; 1:13111315.

3. Wotherspoon AC, Ortiz-Hidalgo C, Falzon MR and Isaacson PG. Helicobacter pylori-associated gastritis and primary B-cell gastric lymphoma. Lancet 1991; 338: 1175-1176.

4. Herrera V and Parsonnet J. Helicobacter pylori and gastric adenocarcinoma. Clin Microbiol Infect. 2009; 15: 971-976.

5. Ram M, Barzilai O, Shapira Y, Anaya JM, Tincani A, Stojanovich L, et al. Helicobacter pylori serology in autoimmune diseases - fact or fiction? Clin Chem Lab Med. 2013; 51:1075-1082.

6. Shin DW, Kwon HT, Kang JM, Park JH, Choi HC, Park MS, et al. Association between metabolic syndrome and Helicobacter pylori infection diagnosed by histologic status and serological status. J Clin Gastroenterol 2012; 46: 840-845.

7. Polyzos SA, Kountouras J, Papatheodorou A, Patsiaoura K, Katsiki E, Zafeiriadou E, et al. Helicobacter pylori infection in patients with nonalcoholic fatty liver disease. Metabolism. 2013; 62(1): 121-126.

8. Papamichael KX, Papaioannou G, Karga H, Roussos A and Mantzaris GJ. Helicobacter pylori infection and endocrine disorders: is there a link? World J Gastroenterol. 2009; 15:2701-2707.

9. Bertalot G, Montresor G, Tampieri M, Spasiano A, Pedroni M, Milanesi B, et al. Decrease in thyroid autoantibodies after eradication of Helicobacter pylori infection. Clin Endocrinol (Oxf) 2004; 61:650-652.

10. Bassi V, Fattoruso O, Polistina MT and Santinelli C. Graves' disease shows a significant increase in the Helicobacter pylori recurrence. Clin Endocrinol (Oxf) 2014; 81:784-785.
11. Yun Mi Choi, Tae Yong Kim, Eui Young Kim, Eun Kyung Jang, Min Ji Jeon, Won Gu Kim, et al. Association between thyroid autoimmunity and Helicobacter pylori infection.Korean J Intern Med. 2017; 32(2): 309-313.

12. Zhe Shen, Yu'e Qin, Yi Liu, Yi Lu, Stefan Munker, Lihua Chen, et al. Helicobacter pylori Infection Is Associated with the Presence of Thyroid Nodules in the Euthyroid Population. PLoS One. 2013; 8(11): e80042.

13. Bassi V, Marino G, Iengo A, Fattoruso O and Santinelli C. Autoimmune thyroid diseases and Helicobacter pylori: the correlation is present only in Graves' disease. World J Gastroenterol. 2012; 18:1093-1097.

14. Ko GH, Park HB, Shin MK, Park CK, Lee JH, Youn HS, et al. Monoclonal antibodies against Helicobacter pylori cross-react with human tissue. Helicobacter. 1997; 2:210-215.

15. Bassi V, Santinelli C, Iengo A and Romano C. Identification of a correlation between Helicobacter pylori infection and Graves' disease. Helicobacter. 2010; 15: 558-562.

16. Amedei A, Bergman MP, Appelmelk BJ, Azzurri A, Benagiano M, Tamburini C, et al. Molecular mimicry between Helicobacter pylori antigens and $\mathrm{H}+, \mathrm{K}+$-adenosine triphosphatase in human gastric autoimmunity. J Exp Med. 2003; 198: 1147-1156.

17. Tomb JF, White O, Kerlavage AR, Clayton RA, Sutton GG, Fleischmann RD, et al. The complete genome sequence of the gastric pathogen Helicobacter pylori. Nature. 1997; 388:539-547.

18. Delemarre FG, Simons PJ and Drexhage HA. Histomorphological aspects of the development of thyroid autoimmune diseases: consequences for our understanding of endocrine ophthalmopathy. Thyroid. 1996; 6:369-377.

19. Vincenzo Bassi, Olimpia Fattoruso, Maria Teresa Polistina and Crescenzo Santinelli. Graves' disease shows a significant increase in the Helicobacter pylori recurrence. Clinical Endocrinology. 2014; 81, 784-787.

20. Kim YA and Park YJ. Prevalence and risk factors of subclinical thyroid disease. Endocrinol Metab (Seoul) 2014; 29(1):20-29.

21. Hybenova M, Hrda P, Prochazkova J, Stejskal V and Sterzl I. The role of environmental factors in autoimmune thyroiditis. Neuro Endocrinol Lett. 2010; 31:283-289.

22. Jiyao W. Internal medicine. Second. People's Medical Publishing House; 2010. pp. 942-963. 
23. Tomasi PA, Dore MP, Fanciulli G, Sanciu F, Realdi $G$ and Delitala G. Is there anything to the reported association between Helicobacter pylori infection and autoimmune thyroiditis? Dig Dis Sci. 2005;50:385-388.

24. Alborzi A, Soltani J, Pourabbas B, Oboodi B, Haghighat M, Hyati M, et al. Prevalence of Helicobacter pylori infection in children (south of Iran). Diagn Microbiol Infect Dis. 2006; 54: 259-61.

25. Mahmood Soveid, Kazem Hosseini Asl and Gholamhossein Ranjbar Omrani. Infection by Cag A Positive Strains of Helicobacter pylori is Associated with Autoimmune Thyroid Disease in Iranian Patients. Iran. J. Immunol. 2012; 9(1):4852.

26. Larizza D, Calcaterra V, Martinetti M, Negrini R, De Silvestri A, Cisternino M, et al. Helicobacter pylori infection and autoimmune thyroid disease in young patients: the disadvantage of carrying the human leukocyte antigens DRB $1 * 0301$ allele. J Clin Endocrinol Metab. 2006; 91:176-9.

27. Franceschi F, Satta MA, Mentella MC, Penland R, Candelli M, Grillo RL, et al. Helicobacter pylori infection in patients with Hashimoto's thyroiditis. Helicobacter. 2004;9:369.

28. Novikova VP, Iur'ev VV, Tkachenko EI, Strukov EL, Liubimov IuA and Antonov PV. Chronic gastritis in children with concomitant diseases of the thyroid gland. Eksp Klin Gastroenterol. 2003;50:40-43, 114.

29. de Luis DA, Varela C, de La Calle H, Canton R, de Argila CM, San Roman AL, et al. Helicobacter pylori infection is markedly increased in patients with autoimmune atrophic thyroiditis. J Clin Gastroenterol. 1998;26(4):259-63.
30. Tomer Y, Barbesino G, Greenberg DA, Concepcion $\mathrm{E}$ and Davies TF. Mapping the major susceptibility loci for familial Graves' and Hashimoto's diseases: evidence for genetic heterogeneity and gene interactions. J Clin Endocrinol Metab 1999; 84: 4656-4664.

31. Tamai H, Ohsako N, Takeno K, Fukino O, Takahashi H, Kuma K, et al. Changes in thyroid function in euthyroid subjects with a family history of Graves' disease: a follow-up study of 69 patients. J Clin Endocrinol Metab 1980; 51: 1123-1127.

32. Villanueva R, Greenberg DA, Davies TF and Tomer Y. Sibling recurrence risk in autoimmune thyroid disease. Thyroid. 2003; 13:761-764.

33. Haim Shmuely, Ilan Shimon, and Limor Azulay Gitter. Helicobacter pylori infection in women with Hashimoto thyroiditis. A case-control study. Medicine (Baltimore). 2016; 95(29): e4074.

34. Mendall MA1, Goggin PM, Molineaux N, Levy J, Toosy T, Strachan D, et al. Childhood living conditions and $H$. pylori seropositivity in adult life. Lancet, 1992; 339(8798):896-897.

35. Ponzetto A, Pellicano R, Morgando A, Cirillo D, Marchiaro G, Curti F, et al. Seroprevalence of Helicobacter pylori infection among blood donors in Torino, Italy. Minerva Gastroenterol Dietol. $2001 ; 47: 3-7$.

36. Malaty HM, El-Kasabany A, Graham DY, Miller CC, Reddy SG, Srinivasan SR, et al. Age at acquisition of Helicobacter pylori infection: a follow-up study from infancy to adulthood. Lancet 2002; 359(9310):931-935.

37. Shi WJ, Liu W, Zhou XY, Ye F and Zhang GX. Associations of Helicobacter pylori infection and cytotoxin-associated gene A status with autoimmune thyroid diseases: a meta-analysis. Thyroid. 2013; 23:1294-1300. 